\title{
Chitin and chitin-cellulose composite hydrogels prepared by ionic liquid-based process as the novel electrolytes for electrochemical capacitors
}

\author{
Dawid Kasprzak ${ }^{1}$ (D) Maciej Galiński ${ }^{1}$
}

Received: 24 July 2021 / Revised: 21 August 2021 / Accepted: 22 August 2021 / Published online: 30 August 2021

(c) The Author(s) 2021

\begin{abstract}
This paper reports on the preparation and electrochemical performance of chitin- and chitin-cellulose-based hydrogel electrolytes. The materials were prepared by a casting solution technique using ionic liquid-based solvents. The method of chitin dissolution in ionic liquid with the assistance of dimethyl sulfoxide co-solvent was investigated. The obtained membranes were soaked with 1-M lithium sulfate aqueous solution. The prepared materials were preliminarily characterized in terms of structural and physicochemical properties. Further, the most promising biopolymer membranes were assembled with activated carbon cloth electrodes in symmetric electrochemical capacitor cells. The electrochemical performances of these devices were studied in a 2-electrode system by commonly known electrochemical techniques, such as cyclic voltammetry, galvanostatic charge/discharge, and electrochemical impedance spectroscopy. The devices operated at a maximum voltage of $0.8 \mathrm{~V}$. All the investigated materials have shown high efficiency in terms of specific capacitance, power density, and cyclability. The studied capacitors exhibited specific capacitance values in the range of $92-98 \mathrm{~F} \mathrm{~g}^{-1}$, with excellent capacitance retention (ca. 97-98\%) after 20,000 galvanostatic charge and discharge cycles. Taking into account the above information and the eco-friendly nature of the biopolymer, it appears that the prepared chitin- and chitin-cellulose-based hydrogel electrolytes can be promising components for green electrochemical capacitors.
\end{abstract}

Keywords Chitin $\cdot$ Cellulose $\cdot$ Ionic liquid $\cdot$ Dimethylsulfoxide $\cdot$ Supercapacitor

\section{Introduction}

Chitin is widespread in the natural environment and it exhibits fascinating properties from both a practical and environmental point of view [1,2]. Chitin-based materials would be particularly attractive because they may feature, among others, biocompatibility, biodegradability, mechanical strength, or thermal and chemical stability [3]. The literature has indicated a wide array of technology and industry sectors where chitin may show a great application potential [4-10]. However, the hardly soluble nature of this polymer limits its large-scale applications. Thus, despite its desirable and useful properties, chitin remains an untapped biomass resource.

Dawid Kasprzak

dawid.kasprzak@put.poznan.pl

1 Institute of Chemistry and Technical Electrochemistry, Poznan University of Technology, ul. Berdychowo 4, 60-965 Poznan, Poland
The difficulties in chitin processing with traditional solvents derive from its structural composition. Like cellulose, chitin is a linear polysaccharide composed of several thousand (1-4)- $\beta$-D-glucose units, except that a secondary hydroxyl at position C-2 of the hexose repeating unit is replaced by an acetamide group [11, 12]. Both cellulose and chitin polymer chains are arranged in a highly extended hydrogen-bonded structure, which leads to a lack of solubility of these polysaccharides when traditional solvents are used. This phenomenon is reflected in the intensive research on alternative and effective biopolymer solvents [13, 14].

From among proposed ideas, the processing of biopolymers in ionic liquid-based solvents has attracted the greatest interest [15-18]. It has been proven that ionic liquids (ILs, organic salts which are in a liquid state below $100{ }^{\circ} \mathrm{C}$ ) show high efficiency in the dissolution of cellulose or chitin and are moreover eco-friendly and recyclable. The solubility of biopolymers in IL-based solvents is essential for opening up new prospects in the green fabrication processes of materials made of natural polymers. An increasing demand 
for eco-friendly components is noticeable almost in every aspect of modern life and energy storage technologies are no different [19-24]. An Electrochemical Double Layer Capacitor (EDLC), also known as a supercapacitor, is one of such electrochemical energy storage systems, which is a matter of interest in the investigation on new potential biopolymer applications [25-28]. Making the supercapacitor technology more environmentally friendly requires consideration of the application of biopolymer-based hydrogel electrolytes [29].

The electrolyte, besides being an electrode material, is one of the most important components of the energy storage device [30]. In the case of EDLC, it provides the free movement of ions involved in the charge compensation on each electrode. The electrolyte is also crucial for achieving high power performance by EDLC and contributes to the value of energy density (as high as its electrochemical stability). In general, there are various commonly known types of electrolytes, classified as liquid- or solid/quasi-solid-form ones [31]. Liquid electrolytes can be categorized into aqueous, organic, and ionic liquid electrolytes. Each liquid electrolyte type possesses its advantages and disadvantages. Aqueous electrolytes exhibit high ionic conductivity and are safe, low cost, and eco-friendly. However, they exhibit low electrochemical stability resulting from the narrow decomposition voltage of the water [32]. Compared to aqueous ones, organic electrolytes extend cell voltage operation and the operating temperature range. Unfortunately, they have lower ionic conductivity and a higher cost. Additionally, these electrolytes exhibit safety issues, e.g., the flammability, volatility, and toxicity [33]. Ionic liquids are a relatively novel group of EDLC electrolytes [34]. The undisputable advantage of ionic liquids is the tunability of their properties. However, their commercial application in supercapacitors is as yet limited by their high price [35, 36].

Solid- or quasi-solid-state electrolytes are another major group of electrolytes for supercapacitors [37, 38]. The main advantages of a solid-state electrolyte are the reduction of the leakage risk from a capacitor, a lack of necessity to apply a separator, and the simplification of handling in the context of the device preparation procedure. The polymer-based electrolytes are the most extensively investigated materials in this group of electrolytes. Among them, 3 additional types can be distinguished: the solid polymer electrolytes (SPEs), the gel polymer electrolytes (GPEs), and the polyelectrolytes [39]. SPEs comprise a solvent-free salt solution in a polymer host material. The ionic conductivity of SPEs is provided by the movement of salt ions through the polymer chains. By contrast, a GPE is composed of a polymer host swollen by a liquid electrolyte. It exhibits liquid-like ionic conductivity and dimensional stability. A polyelectrolyte consists of macromolecules composed of the charged monomer subunits responsible for ionic conductivity. This study is focused on the GPEs which are swollen by an aqueous electrolyte. Such a material is called a hydrogel polymer electrolyte [40].

Poly(vinyl alcohol) (PVA) is one of the most widely investigated polymers used as a host matrix for hydrogel electrolytes [41]. This frequency of use results from the fact that this synthetic polymer exhibits high structural integrity, high hydrophilicity, chemical stability, nontoxicity, and cost-effectiveness. Importantly, it is easy to handle in the hydrogel preparation by the casting method. Nevertheless, one of the methods for improving the sustainability of electrochemical storage devices is the replacement of synthetic polymer components by environmentally friendly materials obtained from renewable natural sources. In this context, natural polymers have already garnered increasing attention [42-45]. Among the biopolymers, cellulose and chitin are two of the most abundant on earth and thus have a great potential in hydrogel preparation.

In this study, we have presented the preparation and electrochemical characterization of chitin and chitin-cellulose hydrogel electrolytes. We have moreover proposed the casting techniques for obtaining biopolymer membranes. For the preparation of biopolymer solutions, we have introduced a method based on the processing of biopolymers in the ionic liquid solvent with the assistance of a dimethyl sulfoxide (DMSO) co-solvent [46]. Various compositions of solvent systems have been tested for this purpose. Among all the prepared membranes, the most promising materials were tested as hydrogel polymer electrolytes for supercapacitors.

\section{Experimental}

\section{Chemicals}

$\alpha$-Chitin extracted from shrimp shells with an acetylation degree of $96 \%$ was obtained from BioLog (Germany). Chitin particles were ground to a fine powder by an analytical mill and sieved (the fraction of particles of a diameter smaller than $63 \mu \mathrm{m}$ was used). The biopolymer material was not purified further before use. Microcrystalline cellulose powder $(20 \mu \mathrm{m})$ with c.a. $250^{\circ}$ of polymerization (DP) was purchased from Sigma-Aldrich. All biopolymers were dried at $105{ }^{\circ} \mathrm{C}$ before use. 1-Ethyl-3-methylimidazolium acetate ([EMIm] [OAc], purity $>95 \%$ ) was obtained from IoLiTec (Germany) and stored under a dry atmosphere in a glovebox chamber (MBraun Plus, Germany). Dimethyl sulfoxide (P.O. Ch. Poland) was used as received. All other chemicals, including ethanol and water, were of analytical grade. As a liquid electrolyte, we employed 1-M lithium sulfate $\left(\mathrm{Li}_{2} \mathrm{SO}_{4}\right)$ aqueous solution. $\mathrm{Li}_{2} \mathrm{SO}_{4}$ monohydrate (BioUltra, $\geq 99.0 \%$ ) was obtained from Sigma-Aldrich and used for the aqueous solution preparation as received. 


\section{Preparation of biopolymer solutions}

In this work, several different types of biopolymer solutions have been prepared:

- Chitin solutions in neat IL solvents: $0.5,1.0$, and $2.0 \mathrm{wt} \%$ of biopolymer, respectively.

- Chitin solutions in ILIDMSO solvents: 0.5, 1.0, and 2.0 wt $\%$ of biopolymer, respectively; additionally, two different IL to DMSO weight ratios types of solvent compositions have been used: $1: 1$ and 1:3, respectively.

- Five weight percent cellulose solution in IL/DMSO mixture.

- One weight percent of chitin and cellulose-mixed solutions in IL/DMSO mixtures; three different chitin to cellulose weight ratios have been used: $3: 1,1: 1$, and 1:3, respectively.

The chitin solutions in neat IL solvents were prepared by the method described below. First, a certain amount of chitin powder was put into a glass scintillation vial. Then, the vial was filled with $1 \mathrm{~g}$ of IL. The mixture, along with a magnetic stir bar, was sealed with parafilm and immersed in an oil bath. This system was stirred at $800 \mathrm{rpm}$ for $0.5 \mathrm{~h}$ until the full dissolution of chitin. The process was taken at $80^{\circ} \mathrm{C}$. Finally, the specific concentration of chitin in IL solution was obtained.

A modified type of the above method was used for the preparation of chitin solvents in ILIDMSO mixtures. It was observed that the addition of DMSO to the chitin mixture in IL solvent does not cause chitin precipitation, yet it reduces the viscosity of the chitin solution [46]. Thus, it may be concluded that DMSO works well as a viscosity-reducing agent in the processing of chitin. The preparation of chitin solutions in ILIDMSO solvents is described below.

In a typical experiment, a certain chitin solution in IL solvent was prepared exactly as indicated above. Subsequently, the chitin solution was topped up with DMSO and the whole mixture was homogenized at an evaluated temperature $\left(80{ }^{\circ} \mathrm{C}\right)$ under constant stirring $(800 \mathrm{rpm})$ for $0.5 \mathrm{~h}$. The amounts of chitin and DMSO were chosen to obtain the intended concentration of chitin and the intended composition of a solvent mixture at the end of the experiment. The compositions of prepared solutions were described at the top of this paragraph.

The cellulose solution in IL/DMSO solvent mixture was prepared according to the method described previously [16]. Firstly, a certain amount of cellulose powder was added to a glass vial that contained $3 \mathrm{~g}$ of DMSO. Then, the mixture was stirred to obtain a homogeneous suspension. Finally, $1 \mathrm{~g}$ of IL was added to the prepared mixture. The resulting system, along with a magnetic stir bar, was immersed in an oil bath $\left(50^{\circ} \mathrm{C}\right)$ and stirred at $800 \mathrm{rpm}$ for $0.5 \mathrm{~h}$ until the full dissolution of cellulose was achieved. A 5 wt $\%$ concentration was chosen, considering the aspects of system viscosity and consumption of solvent components.

The solutions of mixed biopolymers were prepared using separate solutions of chitin in neat IL and cellulose in ILIDMSO system. To obtain a biopolymer mixture with a specific composition, certain amounts of $1 \mathrm{wt} \%$ chitin solution and $5 \mathrm{wt} \%$ cellulose solution were mixed in a separate glass vial. The composition of the mixture was chosen to obtain the final concentration of the biopolymer (cellulose + chitin) at the level of $1 \mathrm{wt} \%$.

The dissolution of biopolymers was assessed visually and via an optical microscope.

\section{Preparation of biopolymer membranes}

The biopolymer membranes were prepared by a solution casting method (Fig. 1). In a typical experiment, a particular biopolymer solution was hot-poured into a frame silicone form attached to the glass plate. The excess of the solution was removed by an automatic film applicator with a

Fig. 1 The preparation procedure of biopolymer hydrogel electrolytes

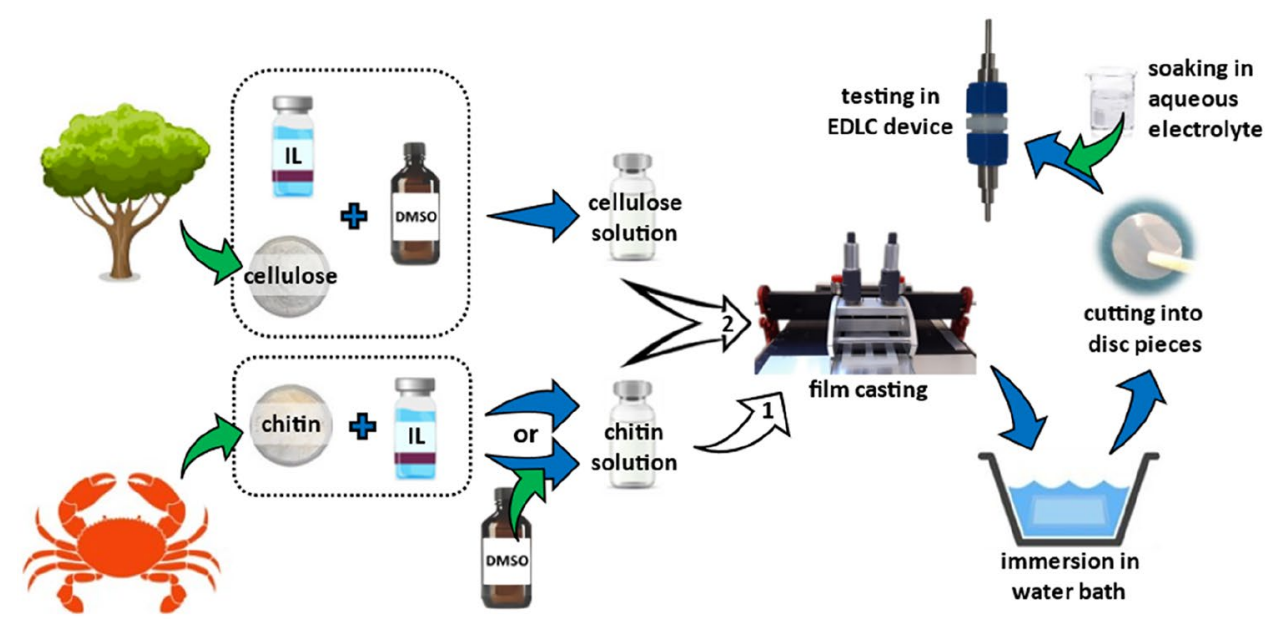


Teflon-coated knife blade. The obtained biopolymer film was immersed in ethanol:deionized water mixture bath. After about $30 \mathrm{~min}$, the prepared hydrogel was put into another container filled with fresh deionized water. On the following day, a biopolymer film was additionally washed several times with fresh deionized water. The washing procedure was performed to completely remove IL (or IL and DMSO) from a biopolymer membrane. Finally, the 1-mm thick disc-shaped pieces with a diameter of $12 \mathrm{~mm}$ were cut off from the biopolymer film sheet with a puncher. Then, the materials were immersed in 1-M lithium sulfate $\left(\mathrm{Li}_{2} \mathrm{SO}_{4}\right)$ aqueous solution and left for swelling overnight. $\mathrm{Li}_{2} \mathrm{SO}_{4}$ aqueous solution was chosen as a liquid-phase component for hydrogel biopolymer electrolytes because it is a wellknown example of the neutral electrolytes [47-49]; it therefore seems to be a non-aggressive and eco-friendly medium. The biopolymer hydrogel electrolytes (Fig. 2) obtained were further characterized by the research techniques described below.

Additionally, in order to carry out a morphological analysis of the hydrogel materials, we have used the freeze-drying process. We assumed that it prevents the shrinkage of the materials, allowing to retain a shape close to original, wet materials. For this purpose, the biopolymer materials were prepared as mentioned above, except they were not been swollen in lithium sulfate solution. Also, the surface area of these samples was different (for each sample ca. $20 \mathrm{~cm}^{2}$ ), for easier implementation in the further characterization. The freeze-drying was used to freeze-dry membranes after they were previously frozen using a laboratory freezer $\left(-25^{\circ} \mathrm{C}\right)$. A high vacuum $(63 \mathrm{~Pa})$ and a temperature of $-25{ }^{\circ} \mathrm{C}$ were employed during the drying process for $72 \mathrm{~h}$. The Christ Alpha 1-2 LDplus freeze dryer (Germany) was used. The morphological features of the lyophilized hydrogel membranes were analyzed by scanning electron microscopy (SEM).

\section{Conductivity test}

The ionic conductivity of hydrogel polymer electrolytes was measured by the electrochemical impedance spectroscopy (EIS) technique in the Swagelok-like cell with two parallel platinum electrodes at constant ambient temperature. The conductivity cell was asymmetrical: a platinum disc with a diameter of $1.5 \mathrm{~mm}$ constituted the working electrode, while a platinum disc with a diameter of ca. $20 \mathrm{~mm}$ constituted an auxiliary electrode. Disc-shaped gel electrolytes were placed between two electrodes during the measurement procedure. The constant gap between the electrodes was fixed to avoid a mechanical failure of membranes. To compare, the ionic conductivity of neat $1 \mathrm{M} \mathrm{Li}_{2} \mathrm{SO}_{4}$ aqueous electrolyte was measured by the EIS method. For this purpose, the conductivity cell with two parallel platinum electrodes was used.

Fig. 2 The image of investigated biopolymer hydrogel electrolytes
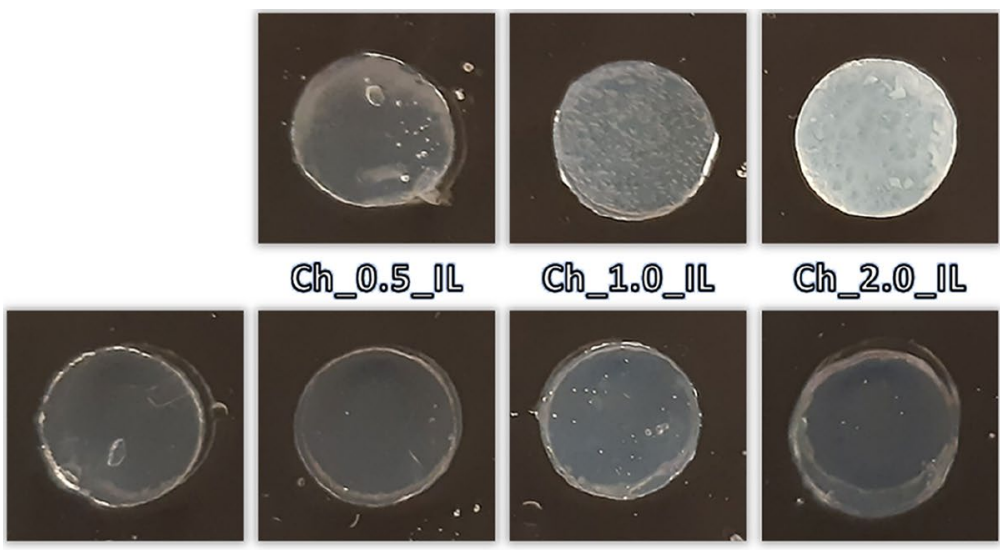

Ch_220_0I
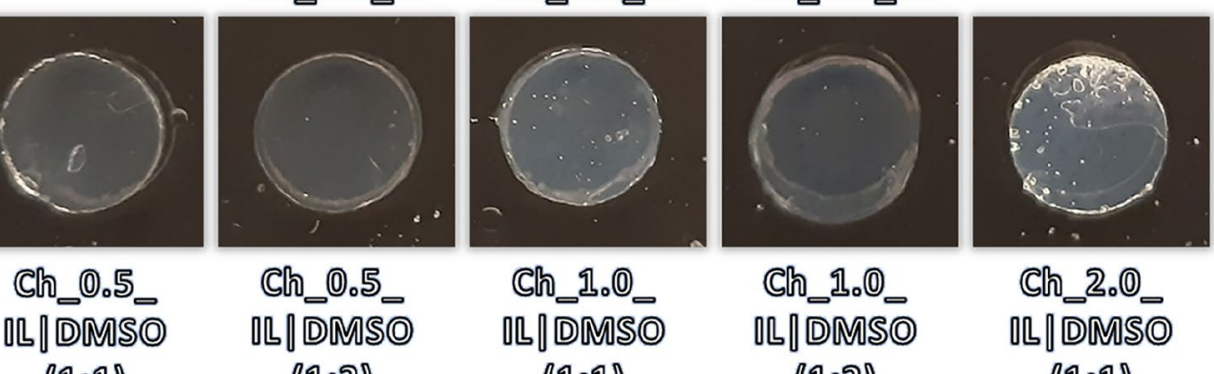

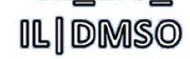

(11.3)

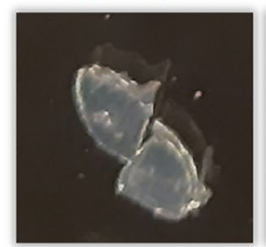

Ch_Cell

(12.3)

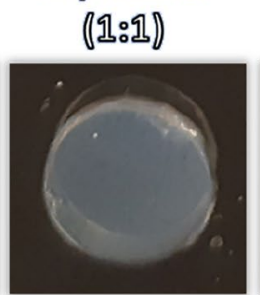

CR_Cell (11:1)

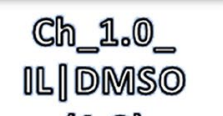

(11.3)

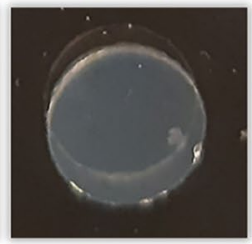

Ch_Cell

(3․11)
Ch_2.0 ⿰⿺乚一匕DMSO (111ㄴ)

$10 \mathrm{~mm}$ 
The cell constant $k$ equaled to $1.19 \mathrm{~cm}^{-1}$. The cell was thermostated at $25^{\circ} \mathrm{C}$.

\section{Structural characterization}

The selected hydrogel polymer electrolytes and the reference materials, e.g., native chitin or regenerated chitin foil, were characterized by using an attenuated total reflectance-Fourier transform infrared spectrometer (ATRFTIR, ALPHA II, Bruker, USA) equipped with a diamond crystal. The FTIR spectra were obtained in the wavenumber region of $4000-400 \mathrm{~cm}^{-1}$. Additionally, the morphology of lyophilized hydrogel membranes was observed by scanning electron microscopy (SEM). The SU3500 Scanning Electron Microscope (Japan) was employed for the measurement. The samples were sprayed with gold before the photographs were taken.

\section{Thermal stability measurements}

Thermogravimetric measurements were carried out using a thermal gravimetric analyzer (TG 209 Libra, Netzsch, Germany). The selected hydrogel polymer electrolytes, reference biopolymer foils, and lithium sulfate monohydrate $\left(\mathrm{Li}_{2} \mathrm{SO}_{4} \times \mathrm{H}_{2} \mathrm{O}\right)$ were investigated. The hydrogel biopolymer electrolytes were superficially dried with tissue paper before the experiment. For each sample, the temperature was scanned from 25 to $600{ }^{\circ} \mathrm{C}$ at a fixed heated rate of $10{ }^{\circ} \mathrm{C} \mathrm{min}^{-1}$. All experiments were performed under a nitrogen purge at a flow rate of $20 \mathrm{ml} \mathrm{min}^{-1}$.

\section{Assembly of EDLC cells}

Electrochemical performances were carried out in Swagelok®-type 2-electrode cells. The symmetric EDLCs were assembled from activated carbon cloth (Kynol® Europa GmbH, ACC-507-20; specific surface area 2000 $\mathrm{m}^{2} \mathrm{~g}^{-1}$ ) used as electrode material and a particular hydrogel biopolymer electrolyte. The objective of the work is the comparison of chitin-based electrolyte processed with and without DMSO assistance as well as chitin-/cellulose-based electrolyte. So, three different samples of an electrolyte, selected on the basis of a preliminary study, were investigated in supercapacitor cells. The host matrices of these electrolytes were the following:

- Chitin form $1.0 \mathrm{wt} \%$ solution in IL (Ch_1.0_IL)

- Chitin form $1.0 \mathrm{wt} \%$ solution in ILIDMSO (1:3) (Ch_1.0_ ILIDMSO (1:3))

- Chitin|Cellulose (1:1) (Ch_Cell (1:1))

Additionally, a reference system with the commercial separator (GF/A, Whatman) soaked with 1-M lithium sulfate
$\left(\mathrm{Li}_{2} \mathrm{SO}_{4}\right)$ aqueous solution was assembled and tested. In all the investigated EDLCs, current collectors made of gold were used.

\section{Electrochemical performance}

The electrochemical performance of assembled EDLCs was characterized by commonly known electrochemical techniques: cyclic voltammetry (CV), electrochemical impedance spectroscopy (EIS), and galvanostatic charge/ discharge (GCD). All the tests were performed on a multichannel potentiostat/galvanostat Interface 5000 device (Gamry Instruments, USA). Voltamperometric measurements were taken at sweep rates from 2.5 to $100 \mathrm{mV} \mathrm{s}^{-1}$, and galvanostatic cycling was carried out at constant current densities in the range of $0.1-20.0 \mathrm{~A} \mathrm{~g}^{-1}$. All these tests were conducted in the voltage range of $0-0.8 \mathrm{~V}$ at ambient conditions. The maximum voltage was chosen according to the preliminary study. EIS measurements were carried out applying a potential amplitude of $10 \mathrm{mV}$ and a frequency range from 0.01 to $100 \mathrm{kHz}$ at ambient conditions.

The equations for determining the electrical parameters of investigated capacitors are described below. The specific capacitance values of EDLCs can be obtained from CV (1 and 2), GCD (3), and EIS (4) measurements:

$C=\frac{2 I}{(d V / d t) \cdot m_{E}}$

$C=\frac{2 \int I d t}{\Delta V \cdot m_{E}}$

$C=\frac{2 I}{(\Delta V / \Delta t) \cdot m_{E}}$

$C=\frac{2}{2 \pi \cdot f \cdot Z_{I m} \cdot m_{E}}$

where $I$ is the current, $d V / d t$ is the sweep rate of the potential, $\int I d t$ is the area under $\mathrm{CV}$ curve (cathodic scan), $\Delta V / \Delta t$ is the slope of potential change during discharge, $f$ is the frequency, $Z_{I m}$ is the imaginary impedance, and $m_{E}$ is the mass of the individual electrode.

The important parameters of every electrochemical storage device are energy and power density. In the case of EDLC, the maximum energy density $(E)$ can be calculated using the equation:

$$
E=\frac{C U^{2}}{2}
$$


where $C$ is the specific capacitance of EDLC and $U$ is the operating voltage.

The maximum power density $(\mathrm{P})$ may be calculated as

$P=\frac{E}{t_{d}}$

where $t_{d}$ is the discharge time recorded in the GCD experiment.

For all the tested capacitors, the energy and power density were calculated per mass unit of the whole electrode material of the device.

\section{Results and discussion}

We currently observe an increasing interest in the application of bio-based materials in various areas of science and industry. The concept of the preparation of hydrogel biopolymer electrolytes as an eco-friendly alternative to classical aqueous electrolytes corresponds to this trend. The results of our investigation on bio-based gel electrolytes are summarized below.

\section{Preliminary characterization}

Conductivity measurements have been conducted to evaluate the hydrogel biopolymer electrolytes preliminarily. The conductivity values coupled with the mechanical properties of biopolymer materials were crucial in choosing the electrolytes for further electrochemical tests in EDLC devices. Table 1 presents the data received from conductivity measurements.

As can be seen, most chitin-based hydrogel electrolytes exhibited similar conductivity values, about $60-70 \mathrm{mS} \mathrm{cm}^{-1}$. These values are comparable to that of neat $1-\mathrm{M} \mathrm{Li}_{2} \mathrm{SO}_{4}$ aqueous electrolyte (ca. $69 \mathrm{mS} \mathrm{cm}^{-1}$ ), but these are slightly higher than the conductivity of a glass fiber membrane soaked in 1- $\mathrm{M} \mathrm{Li}_{2} \mathrm{SO}_{4}\left(54 \mathrm{mS} \mathrm{cm}{ }^{-1}\right)$. Conversely, the membranes obtained from $2 \mathrm{wt} \%$ chitin solutions show relatively low conductivity values, ca. $25-45 \mathrm{mS} \mathrm{cm}^{-1}$. Probably, a higher membrane packing density causes the ion mobility decrease in these electrolytes.

The hydrogel electrolytes based on chitin-cellulose composites exhibited conductivity values ca. $50-65 \mathrm{mS} \mathrm{cm}^{-1}$. However, only 2 from 3 samples remained stable during
Table 1 Specific conductivity values of investigated electrolytes

\begin{tabular}{llc}
\hline Electrolyte & Symbol & $\begin{array}{c}\text { Specific conductivity } \\
\left(\mathbf{m S ~ c m}^{-1}\right)\end{array}$ \\
\hline $1 \mathrm{M} \mathrm{Li} 2 \mathrm{SO}_{4}$ (aqueous) & - & $68.9 \pm 0.5$ \\
\hline $1 \mathrm{M} \mathrm{Li} 2 \mathrm{SO}$ (aqueous-Whatman) & Whatman & 54 \\
$\begin{array}{l}\text { Chitin form 0.5 wt\% solution in } \\
\text { IL }\end{array}$ & Ch_0.5_IL & 67 \\
$\begin{array}{l}\text { Chitin form 1.0 wt\% solution in } \\
\text { IL }\end{array}$ & Ch_1.0_IL & 64 \\
$\begin{array}{l}\text { Chitin form 2.0 wt\% solution in } \\
\text { IL }\end{array}$ & Ch_2.0_IL & 44 \\
Chitin form 0.5 wt\% solution & Ch_0.5_IL|DMSO (1:1) & 66 \\
in IL|DMSO (1:1) & \\
$\begin{array}{l}\text { Chitin form 0.5 wt\% solution } \\
\text { in IL|DMSO (1:3) }\end{array}$ & Ch_0.5_IL|DMSO (1:3) & 65 \\
$\begin{array}{l}\text { Chitin form 1.0 wt\% solution } \\
\text { in IL|DMSO (1:1) }\end{array}$ & Ch_1.0_IL|DMSO (1:1) & 66 \\
$\begin{array}{l}\text { Chitin form 1.0 wt\% solution } \\
\text { in IL|DMSO (1:3) }\end{array}$ & Ch_1.0_IL|DMSO (1:3) & 63 \\
$\begin{array}{l}\text { Chitin form 2.0 wt\% solution } \\
\text { in IL|DMSO (1:1) }\end{array}$ & Ch_2.0_IL|DMSO (1:1) & 26 \\
$\begin{array}{l}\text { Chitin|Cellulose (3:1) } \\
\text { Chitin|Cellulose (1:1) }\end{array}$ & Ch_Cell (3:1) & 65 \\
Chitin|Cellulose (1:3) & Ch_Cell (1:1) & 50 \\
\hline
\end{tabular}

highlighted samples were investigated in electrochemical capacitors measurement error (for hydrogel electrolytes) $\pm 5 \mathrm{mS} \mathrm{cm}^{-1}$ 
conductivity measurements. The sample obtained from 1 wt $\%$ chitin-cellulose (1:3) solution was very susceptible to damage and therefore its conductivity was not measured.

According to the measurement results of ionic conductivity as well as on the basis of the mechanical properties observed, the samples of hydrogel electrolytes assigned with the following symbols were chosen for further investigation: Ch_1.0_IL, Ch_1.0_ILIDMSO (1:3), and Ch_Cell (1:1). Ch_1.0_IL shows the highest conductivity values from all the samples obtained from neat IL. Ch_1.0_ILIDMSO (1:3) exhibited high ionic conductivity and good mechanical properties, but it also helped to reduce the amount of IL used for the electrolyte preparation. Ch_Cell (1:1) sample was composed from equal amounts of two different biopolymers and was thus an interesting hybrid material with good electrochemical and mechanical properties.

Figure 3 presents the Fourier transform infrared spectroscopy (FTIR) analysis of the investigated hydrogel electrolytes as well as reference materials: native chitin powder and chitin foil. The latter sample was obtained by washing the chitin membrane with deionized water and subsequently drying it in a laboratory dryer. Figure 3 a shows the FTIR spectra of chitin powder, regenerated chitin foil, and hydrogel chitin electrolyte (Ch_1.0_IL). As can be seen, the FTIR spectra of native chitin and regenerated chitin foil are almost the same. There are no additional absorbency peaks and no peak shifting or vanishing. It could be suggested that no chemical derivatization or degradation takes place during chitin processing in IL. Furthermore, there is no residue of IL in the regenerated material. Ch_1.0_IL differs from other chitin samples because this material was soaked with an aqueous electrolyte. However, some similarities to dry chitin samples are still visible. While analyzing this FTIR spectrum, an intensive and broad peak observed at the range of $3000-3600 \mathrm{~cm}^{-1}$ comes from $\mathrm{O}-\mathrm{H}$ stretching vibration [50]. At the top of this absorption bandwidth, a small peak at $3260 \mathrm{~cm}^{-1}$ can be seen, attributable to the stretching vibrational mode of the $\mathrm{NH}$ groups in chitin [51]. The $\mathrm{O}-\mathrm{H}$ bending modes are present between 1600 and $1700 \mathrm{~cm}^{-1}$. The broad peak at around $1100 \mathrm{~cm}^{-1}$ is attributed to sulfate groups [52, 53]. This signal overlays the chitin diagnostic peaks from that spectrum area. Similarly, the strong and broad absorption band at the range of $400-800 \mathrm{~cm}^{-1}$ attributable to water almost completely overlays all peaks associated with chitin. As might be expected, the FTIR analysis led to the assumption that the investigated hydrogel biopolymer electrolyte is purely composed of chitin and aqueous $\mathrm{Li}_{2} \mathrm{SO}_{4}$ electrolyte.

Figure $3 \mathrm{~b}$ correlates the FTIR spectra of chitin-cellulose composite hydrogels with the reference spectra of neat chitin and neat cellulose hydrogels. The spectral characteristic of composite hydrogels takes the form of a hybrid of two components: neat chitin and neat cellulose hydrogels. Generally, the diagnostic absorption peaks of chitin are becoming less intense with the increasing amount of cellulose concentration in the composite sample. It is particularly visible in the case of peaks attributed to the presence of $\mathrm{NH}$ groups, at 3260,1555 , and $1380 \mathrm{~cm}^{-1}$ [54].

The morphology analysis of the freeze-dried of the investigated chitin-based hydrogel electrolytes is presented in Fig. 4. Additionally, there is a SEM image of the cellulose hydrogel membrane (Fig. 4e), which we have investigated as the reference sample. As can be seen, all the investigated materials exhibited porous surface morphology. There
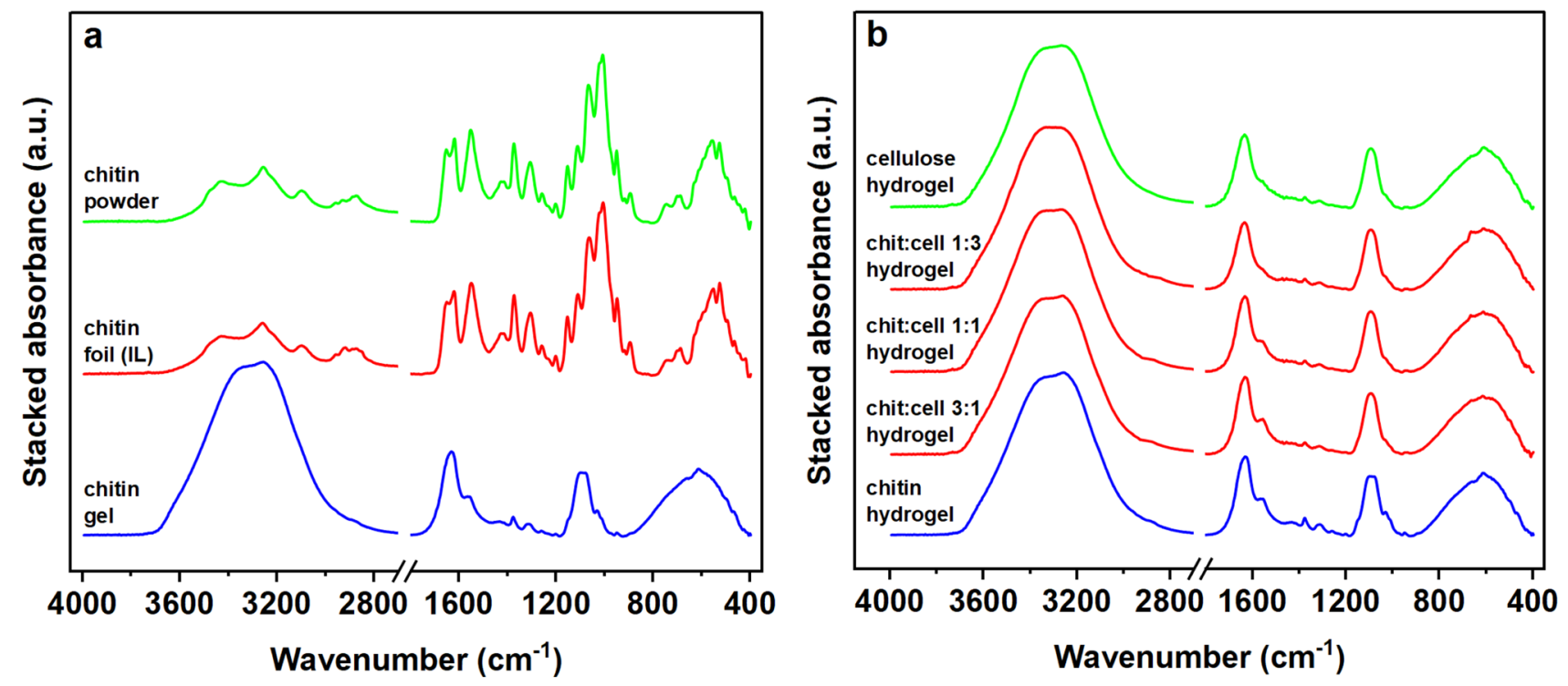

Fig. 3 The comparison of FTIR spectra of various chitin-based materials (a) and chitin, cellulose, and chitin-cellulose hydrogels (b) 

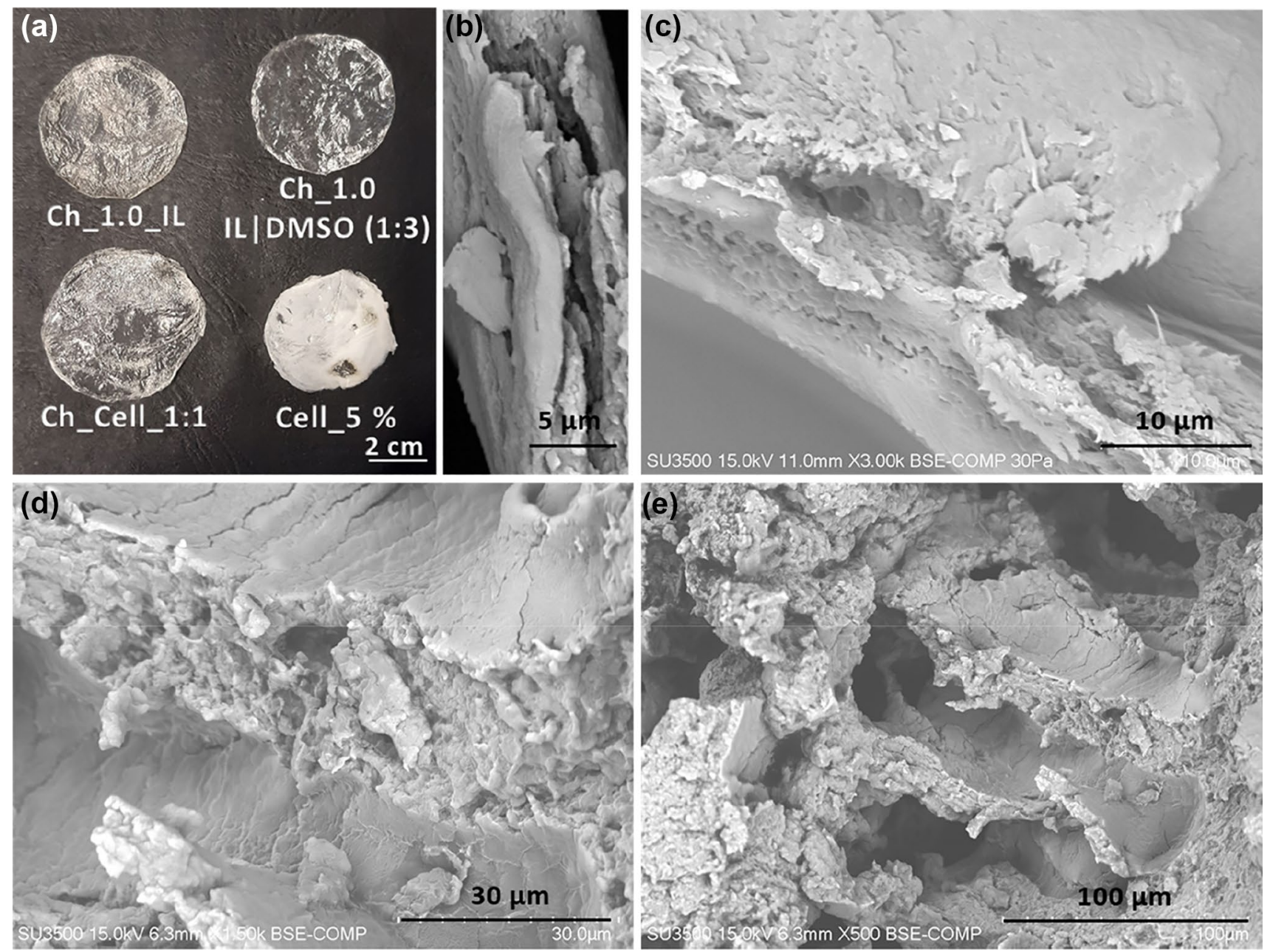

Fig. 4 Morphological analysis of lyophilized hydrogel membranes: image of tested samples (a) and SEM micrographs of cross-section for freeze-dried Ch_1.0_IL (b), Ch_1.0_ILIDMSO (1:3) (c), Ch_Cell_1:1 (d), and Cell_5\% (e) samples
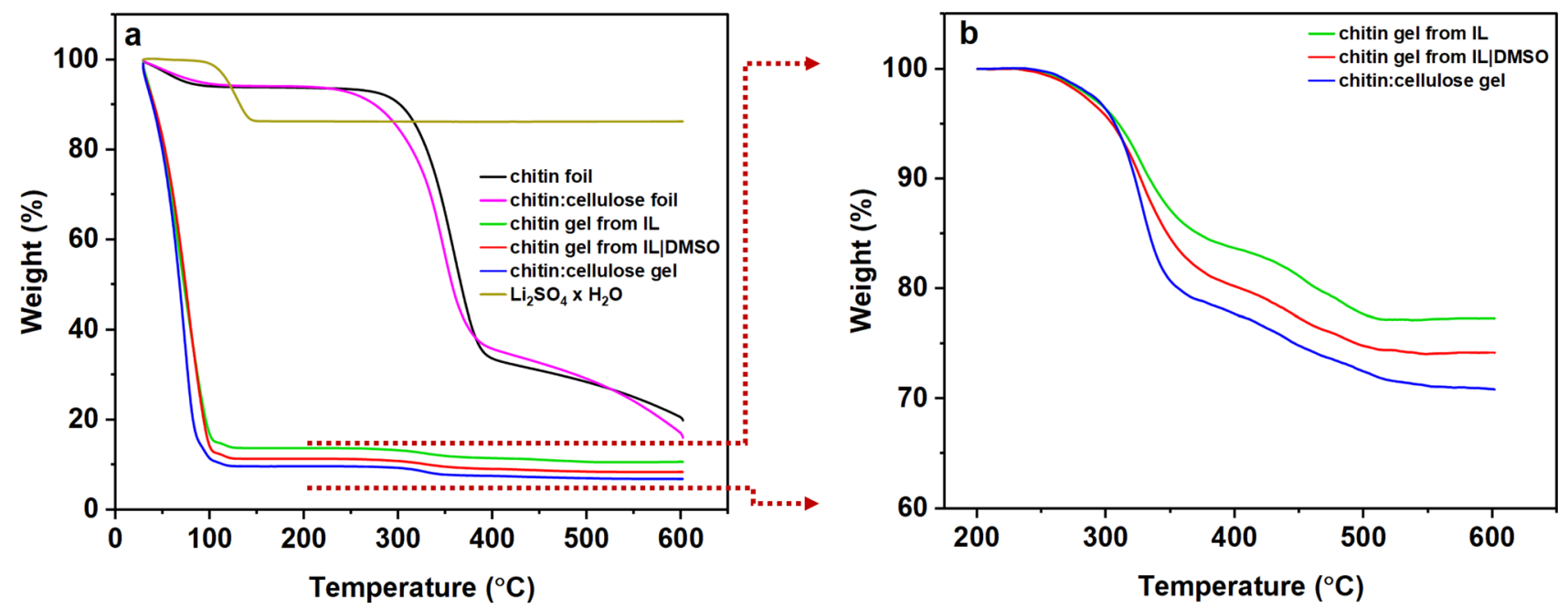

Fig. 5 Thermogravimetric analysis of the investigated biopolymer hydrogel electrolytes and reference samples 

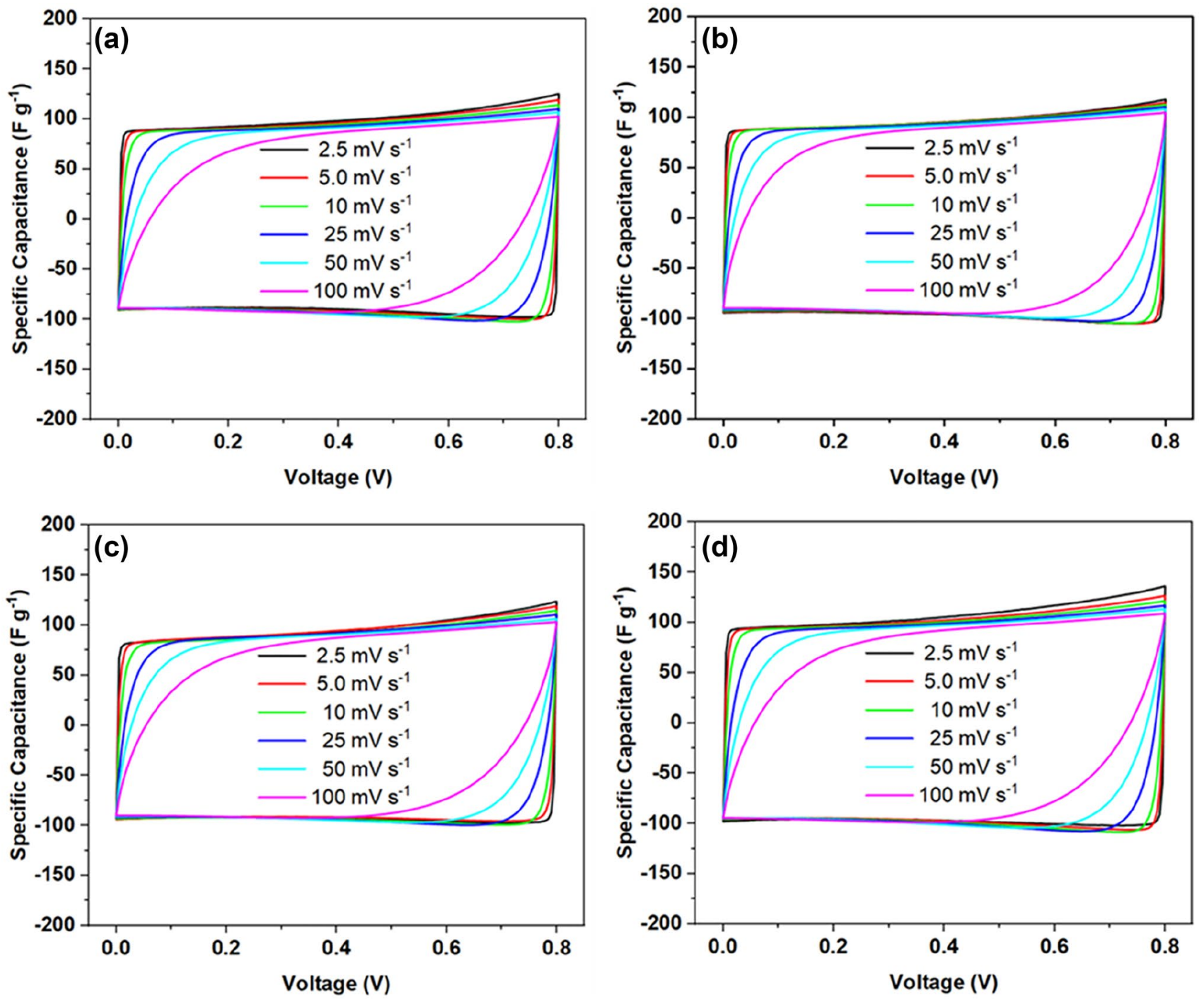

Fig. 6 Cyclic voltammograms of EDLCs containing Ch_1.0_IL (a), Ch_1.0_ILIDMSO (1:3) (b), Ch_Cell (1:1) (c), or $1 \mathrm{M} \mathrm{Li}_{2} \mathrm{SO}_{4}$ aqueous electrolyte (d) as an electrolyte

are open channels mixed with smoother interconnecting domains. It is probably due to the growth of relatively large ice crystals during the freeze-drying from water $[55,56]$. The applied drying method does not prevent the collapsing of sponge-like channels of biopolymers membranes; nevertheless, it provided basic information about the porous surface morphology of investigated materials. We assumed that the channel-like network is crucial in providing well soaking of a biopolymeric matrix with liquid electrolyte, and thus, it is the guarantee of an excellent ionic conductivity of the electrolyte.

Figure 5 shows the results of thermal gravimetric analysis (TGA) of hydrogel biopolymer electrolytes. Additionally, cellulose and chitin foils as well as neat lithium sulfate monohydrate $\left(\mathrm{Li}_{2} \mathrm{SO}_{4} \times \mathrm{H}_{2} \mathrm{O}\right)$ were investigated as the reference samples. Both chitin and chitin-cellulose foils demonstrated about $5 \%$ weight loss up to $105{ }^{\circ} \mathrm{C}$, which corresponds to the evaporation of water. The main mass decline of hydrogel electrolytes is also observed in the temperature range of ca. $25-105{ }^{\circ} \mathrm{C}$. Of course, the weight loss recorded for hydrogels is much higher compared to biopolymer foils. The electrolytes lost $80-85 \%$ of their initial mass up to $105{ }^{\circ} \mathrm{C}$. Additionally, a few percent mass declines of hydrogel electrolytes are observed up to about $150{ }^{\circ} \mathrm{C}$. It corresponds to the residual water content. These water molecules were strongly bonded to the crystal structure of $\mathrm{Li}_{2} \mathrm{SO}_{4}$ and thus the evaporation of residual water was a little harder. This hypothesis is based on the TGA profile of lithium sulfate monohydrate.

The decomposition of chitin foil starts at around $300{ }^{\circ} \mathrm{C}$. The chitin-cellulose composite film starts thermal degradation a little earlier, at around $250{ }^{\circ} \mathrm{C}$. The reduction of the 

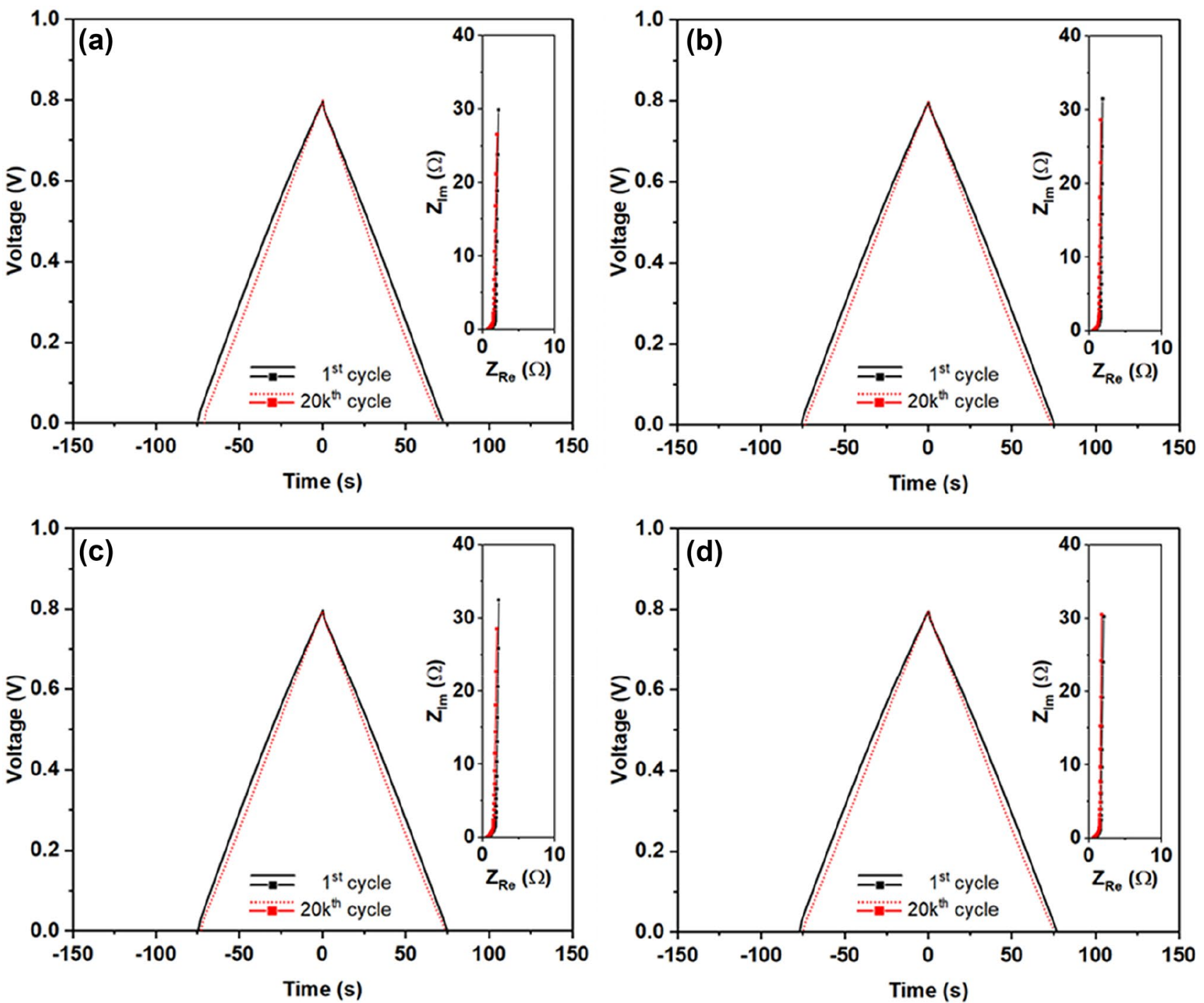

Fig. 7 Galvanostatic charge/discharge curves (at $0.5 \mathrm{~A} \mathrm{~g}^{-1}$ ) and EIS spectra (inset) of EDLCs containing Ch_1.0_IL (a), Ch_1.0_ILIDMSO (1:3) (b), Ch_Cell $(1: 1)(\mathbf{c})$, or $1 \mathrm{M} \mathrm{Li}_{2} \mathrm{SO}_{4}$ aqueous electrolyte (d) as an electrolyte

composite stability compared to neat chitin foil is caused by the presence of cellulose in this material. To better observe the biopolymer degradation in hydrogel biopolymer electrolytes, the results of TGA are thoroughly displayed in Fig. 5b. To facilitate interpretation, the weight losses were recalculated assuming mass value at $200{ }^{\circ} \mathrm{C}$ as an initial weight. As can be seen, the degradation of biopolymer matrices of hydrogel electrolytes starts approximately at $250{ }^{\circ} \mathrm{C}$. In contrast to biopolymer foils, there is no significant difference in the onset decomposition temperatures of hydrogel electrolytes. This study concluded that the biopolymer-based electrolytes could be thermally stable below the decomposition temperatures of its biopolymer components. Of course in the case of the operating conditions, the significantly lower temperature limits the use of hydrogel electrolytes. However, this experiment offers important information in the context of the recycling of electrochemical storage devices.

\section{Electrochemical performance}

Figure 6 shows cyclic voltammograms of activated carbon cloth electrodes assembled in EDLC cells with 4 different electrolytes (listed according to their symbols, see Table 1): Ch_1.0_IL (Fig. 6a), Ch_1.0_ILIDMSO (1:3) (Fig. 6b), Ch_ Cell (1:1) (Fig. 6c), and 1-M Li $\mathrm{SO}_{4}$ aqueous electrolyte (Fig. 6d). All of the investigated capacitors show comparable electrochemical characteristics. The cyclic voltammograms display a box-type shape with excellent charge propagation. There is no response from the redox reaction and the systems reflect purely capacitive behavior. The charge propagation 
Table 2 Selected electrochemical parameters of the investigated EDLCs

\begin{tabular}{|c|c|c|c|c|c|c|}
\hline \multirow[t]{3}{*}{ Electrolyte } & \multicolumn{6}{|c|}{ Specific capacitance $\left(\mathrm{F} \mathrm{g}^{-1}\right)$} \\
\hline & \multicolumn{2}{|l|}{ CV } & \multicolumn{2}{|l|}{ GCD } & \multirow{2}{*}{$\begin{array}{l}\text { EIS } \\
\operatorname{EDR}(\Omega)\end{array}$} & \multirow{2}{*}{$\begin{array}{l}\text { GCD } 20 k^{\text {th }} \\
\text { Ceff }(\%)\end{array}$} \\
\hline & $2.5\left(\mathrm{mV} \mathrm{s}^{-1}\right)$ & $100\left(\mathrm{mV} \mathrm{s}^{-1}\right)$ & $0.1\left(\mathrm{~A} \mathrm{~g}^{-1}\right)$ & $20\left(\mathrm{~A} \mathrm{~g}^{-1}\right)$ & & \\
\hline Ch_IL & 93 & 75 & 92 & 42 & 1.7 & 96.7 \\
\hline Ch_ILIDMSO & 97 & 80 & 96 & 55 & 1.5 & 97.1 \\
\hline Ch_Cell & 93 & 75 & 95 & 47 & 1.7 & 98.2 \\
\hline Whatman & 98 & 80 & 98 & 55 & 1.5 & 97.6 \\
\hline
\end{tabular}

gradually decreases with the increasing scan rate (from 2.5 to $100 \mathrm{mV} \mathrm{s}^{-1}$ ) and a deviation from a rectangular shape of $\mathrm{CV}$ curves is observed for all the tested devices. This is typical capacitor behavior. The initial specific capacitances calculated for capacitors based on tested hydrogel electrolytes are ca. 93-97 $\mathrm{F} \mathrm{g}^{-1}$, which are similar values as one estimated for EDLC with reference aqueous electrolyte (98 $\mathrm{F} \mathrm{g}^{-1}$ ). The results from $\mathrm{CV}$ measurements demonstrate that the investigated hydrogel biopolymer electrolytes exhibit properties comparable to those of liquid electrolytes, characterized by high ionic conductivity and good electrode wettability.

Figure 7 presents galvanostatic charge/discharge measurements recorded for all the investigated EDLC systems. For each tested capacitor, GCD profiles obtained from the 1 st and 20000 th cycles have been discussed. The typical triangular shape of the charge/discharge curves with a small potential drop for all the systems is observed. The shape of the GCD curves is almost identical over 20000 cycles and only slightly differs compared to the initial ones. The starting values of specific capacitance calculated from this measurement for tested capacitors were ca. $92-98 \mathrm{~F} \mathrm{~g}^{-1}$. Additionally, the impedance analysis of the investigated EDLCs has been presented (Fig. 6 inset plots). For each system, the Nyquist plots recorded after the 1st and 20,000th GCD cycle exhibit similar shapes. The impedance spectra are shifted towards the lower impedance values and they take a straight line profile in the low-frequency region, indicating good capacitive behavior and low internal resistance. This observation proves the conclusions drawn from GCD measurements and from $\mathrm{CV}$ tests. The selected electrochemical parameters determined from these measurements are summarized in Table 2.

The behavior of the above capacitors was also studied more thoroughly by using the results obtained from $\mathrm{CV}$ and GCD measurements. Figure 8 illustrates how well the investigated capacitors retain their initial capacitance along with the increasing voltage rate and the increasing current density. As can be seen, the capacitance retention calculated from CVs (Fig. 8a) for all the tested systems only slightly decreases with the increasing scan rate. All hydrogel-based capacitors exhibit almost the same characteristic as the
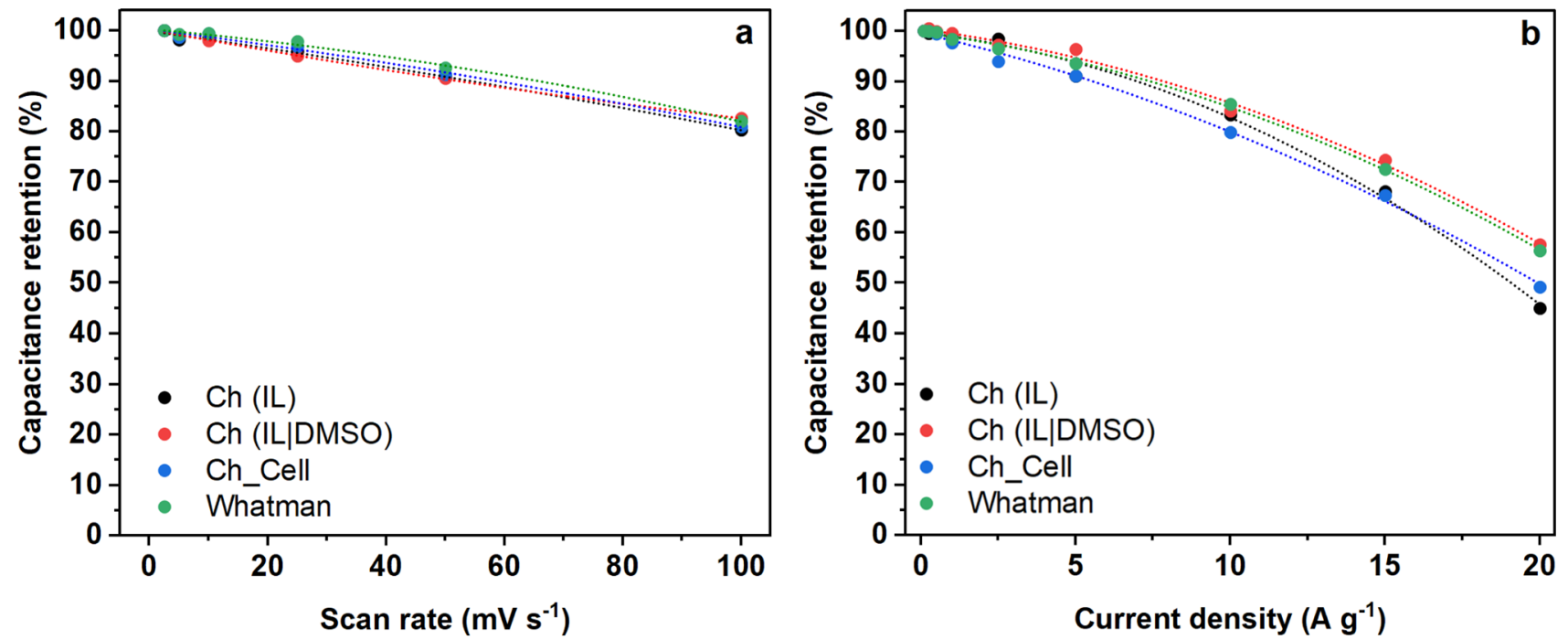

Fig. 8 Capacitance retention of the investigated EDLCs calculated from CVs at scan rates from 2.5 to $100 \mathrm{mV} \mathrm{s}^{-1}$ (a) and from GCD measurements at current densities from 0.1 to $20 \mathrm{~A} \mathrm{~g}^{-1}(\mathbf{b})$ 

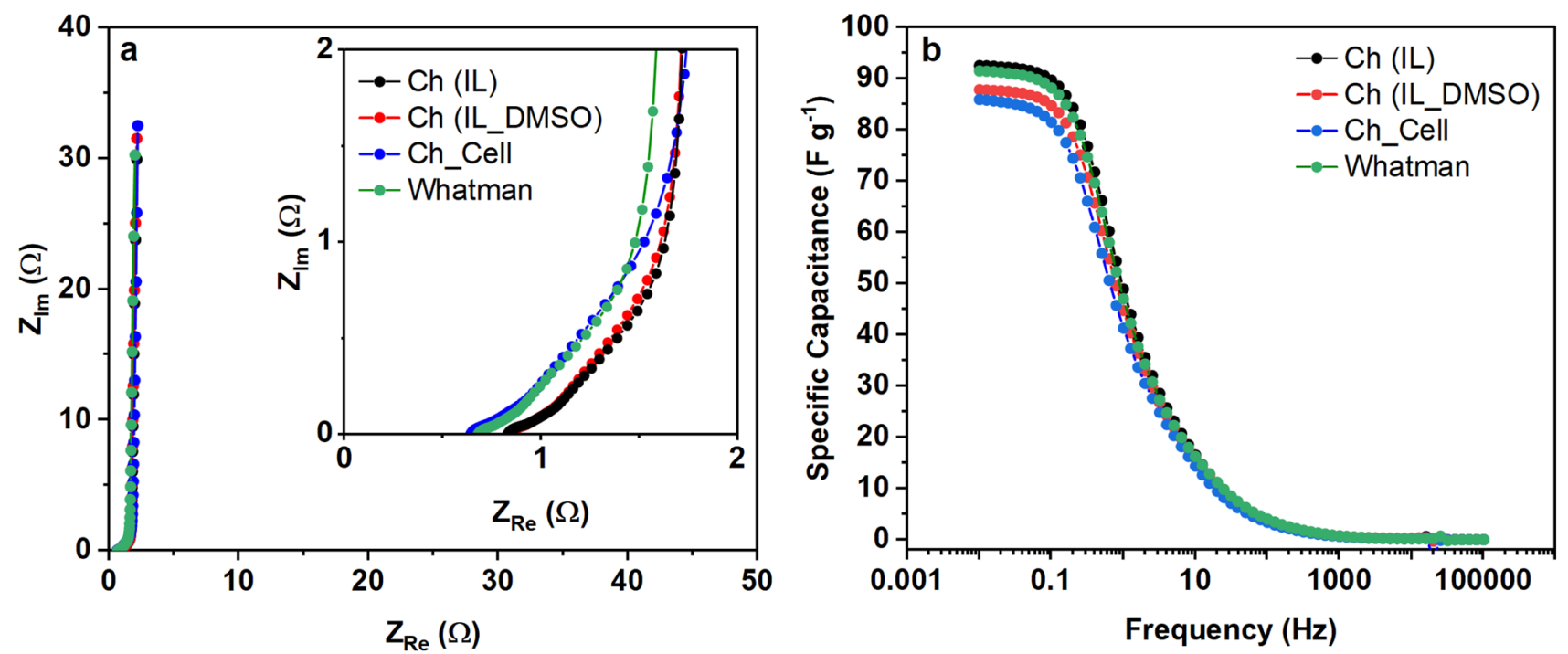

Fig. 9 Impedance analysis of EDLCs based on the investigated electrolytes

system containing an aqueous electrolyte. They display ca. $80 \%$ of their initial capacitance at $100 \mathrm{mV} \mathrm{s}^{-1}$. Similar observations have been found in GCD studies. Capacitors retained ca. 80-90\% of their initial capacitance at $10 \mathrm{~A} \mathrm{~g}^{-1}$, but they also have exhibited more than half the capacitance retention at current density as high as $20 \mathrm{~A} \mathrm{~g}^{-1}$. This implies that electrode materials of tested capacitors are well-soaked in prepared hydrogel polymer electrolytes as well as in an aqueous electrolyte.

The Nyquist plots of all the tested EDLC cells are compared in Fig. 9a. All of the impedance spectra almost overlap one another and shift towards the lower impedance values. In the low-frequency region, the impedance profile for each EDLC cell is a straight line with an absence of a semicircle.
It indicates a good capacitive behavior with good contact between the electrode material and the current collector. The determined equivalent distributed resistance (EDR) values are in the range of 1.5-2.0 $\Omega$ for all the EDLCs studied. The results suggest a similarity in the power profiles of the investigated devices. Figure $9 \mathrm{~b}$ presents the analysis of the capacitances obtained from EIS measurements. In a low-frequency region $(10-100 \mathrm{mHz})$, the specific capacitance of the systems tested reached ca. 85-95 $\mathrm{F} \mathrm{g}^{-1}$. It corresponds to the results from $\mathrm{CV}$ and $\mathrm{GCD}$, measured at relatively low scan rates and low current densities, respectively. The capacitance decreases with the increasing values of frequency, which is the typical behavior of EDLC cells.
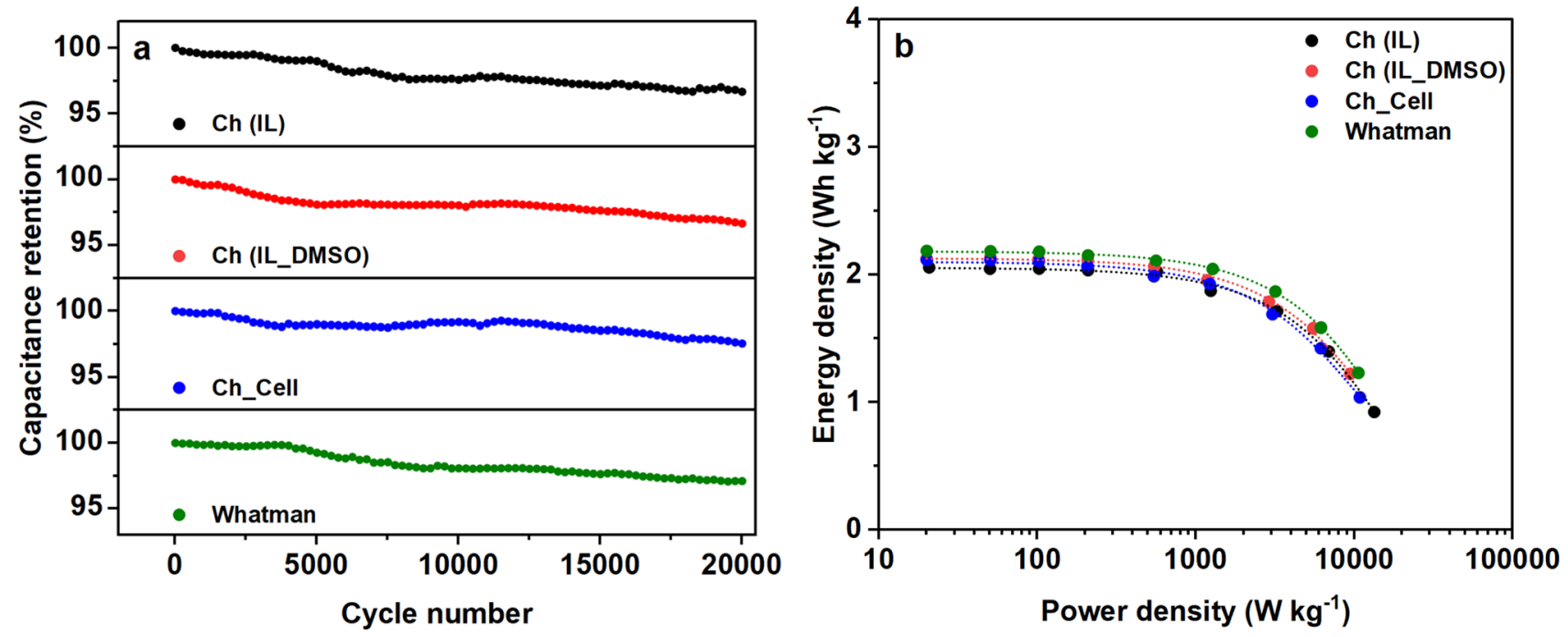

Fig. 10 Cycling stability over 20,000 cycles at $0.5 \mathrm{~A} \mathrm{~g}^{-1}$ (a) and Ragone plot (b) of EDLCs based on the investigated electrolytes 
One of the most important advantages of supercapacitors is their long lifecycle. To study that aspect, a constant current charge/discharge measurement at $0.5 \mathrm{~A} \mathrm{~g}^{-1}$ was used (Fig. 10a). Upon 20,000 cycles, the electrochemical efficiency of all the tested devices provides excellent capacitance retention. It has been shown that the cyclic stability of capacitors assembled with hydrogel biopolymer electrolytes is as high as in the case of devices based on aqueous electrolytes. Generally, all the investigated capacitors have shown extremely good cycling stability, displaying more than $97 \%$ starting capacitance over thousands of GCD cycles.

The final comparison of the EDLC devices tested is presented in Fig. 10b in a so-called Ragone plot. The powerenergy density profiles have been determined on the basis of GCD measurements. The energy and power densities have been calculated for the maximum operating voltage according to Eqs. (4) and (5), respectively. Almost constant energy profile in the range of power densities of $10-1000 \mathrm{~W} \mathrm{~kg}^{-1}$ is observed, indicating an excellent capacitive performance of the investigated materials. This dependence shows that all the devices tested display comparable energy performance of ca. 2.0-2.2 $\mathrm{Wh} \mathrm{kg}^{-1}$.

\section{Conclusions}

It has been reported that chitin and chitin-cellulose composite materials can be successfully applied as hydrogel biopolymer electrolytes after processing in IL-based solvents. The chitin and chitin-cellulose membranes were prepared by a casting solution technique. For the preparation of biopolymer solutions, we introduced a new method based on the processing of biopolymers in neat IL or the IL-based solvent with the assistance of dimethyl sulfoxide (DMSO) co-solvent. The materials obtained were preliminarily characterized and then applied in electrochemical capacitors assembled with activated carbon cloth electrode materials. The electrochemical performance of the EDLC cells was investigated by various common research techniques and compared to the device containing reference aqueous electrolyte. The fabricated hydrogel biopolymer electrolytes proved to be as efficient as the reference aqueous electrolyte. They display excellent electrochemical performance in terms of specific capacitance, power density, and cyclability. Finally, due to the eco-friendly nature of the biopolymer, the prepared hydrogel electrolytes appear to be the promising components for green electrochemical capacitors.

Funding This work was performed with the financial support of the National Science Centre, Poland (grant no. 2019/33/N/ST5/01598), and Poznan University of Technology (grant no. 0911/SBAD/2102).

\section{Declarations}

Competing interests The authors declare no competing interests.

Open Access This article is licensed under a Creative Commons Attribution 4.0 International License, which permits use, sharing, adaptation, distribution and reproduction in any medium or format, as long as you give appropriate credit to the original author(s) and the source, provide a link to the Creative Commons licence, and indicate if changes were made. The images or other third party material in this article are included in the article's Creative Commons licence, unless indicated otherwise in a credit line to the material. If material is not included in the article's Creative Commons licence and your intended use is not permitted by statutory regulation or exceeds the permitted use, you will need to obtain permission directly from the copyright holder. To view a copy of this licence, visit http://creativecommons.org/licenses/by/4.0/.

\section{References}

1. Dutta PK, Duta J, Tripathi VS (2004) Chitin and chitosan: chemistry, properties and applications. J Sci Ind Res (India) 63:20-31. https://doi.org/10.1002/chin.200727270

2. Ehrlich H, Koutsoukos PG, Demadis KD, Pokrovsky OS (2008) Principles of demineralization: modern strategies for the isolation of organic frameworks. Part I. Common definitions and history Micron 39:1062-1091. https://doi.org/10.1016/j.micron.2008.02. 004

3. Tsurkan MV, Voronkina A, Khrunyk Y et al (2021) Progress in chitin analytics. Carbohydr Polym 252:117204. https://doi.org/10. 1016/j.carbpol.2020.117204

4. Kolodziej A, Fic K, Frackowiak E (2015) Towards sustainable power sources: chitin-bound carbon electrodes for electrochemical capacitors. J Mater Chem A 3:22923-22930. https://doi.org/10. 1039/C5TA06750B

5. Ravi Kumar MNV (2000) A review of chitin and chitosan applications. React Funct Polym 46:1-27. https://doi.org/10.1016/S13815148(00)00038-9

6. Park BK, Kim M-M (2010) Applications of chitin and its derivatives in biological medicine. Int J Mol Sci 11:5152-5164. https:// doi.org/10.3390/ijms11125152

7. Younes I, Rinaudo M (2015) Chitin and chitosan preparation from marine sources. Structure, properties and applications. Mar Drugs 13:1133-1174. https://doi.org/10.3390/md13031133

8. Shamshina JL, Kelly A, Oldham T, Rogers RD (2020) Agricultural uses of chitin polymers. Environ Chem Lett 18:53-60. https://doi.org/10.1007/s10311-019-00934-5

9. Chakravarty J, Semerdzhiev D, Silby MW et al (2019) Properties of solvent-cast chitin membranes and exploration of potential applications. Materialia 8:100452. https://doi.org/10.1016/j.mtla. 2019.100452

10. Aranaz I, Acosta N, Civera C et al (2018) Cosmetics and cosmeceutical applications of chitin, chitosan and their derivatives. Polymers (Basel) 10:213-238. https://doi.org/10.3390/ polym 10020213

11. Klemm D, Heublein B, Fink HP, Bohn A (2005) Cellulose: fascinating biopolymer and sustainable raw material. Angew Chemie - Int Ed 44:3358-3393. https://doi.org/10.1002/anie.200460587

12. Rinaudo M (2006) Chitin and chitosan: Properties and applications. Prog Polym Sci 31:603-632. https://doi.org/10.1016/j. progpolymsci.2006.06.001

13. Zhong Y, Cai J, Zhang LN (2020) A review of chitin solvents and their dissolution mechanismS. Chinese J Polym Sci (English Ed 38:1047-1060. https://doi.org/10.1007/s10118-020-2459-x 
14. Jaworska MM, Kozlecki T, Gorak A (2012) Review of the application of ionic liquids as solvents for chitin. J Polym Eng 32:67-69. https://doi.org/10.1515/polyeng-2011-0145

15. Swatloski RP, Spear SK, Holbrey JD, Rogers RD (2002) Dissolution of cellose with ionic liquids. J Am Chem Soc 124:4974-4975. https://doi.org/10.1021/ja025790m

16. Kasprzak D, Krystkowiak E, Stępniak I, Galiński M (2019) Dissolution of cellulose in novel carboxylate-based ionic liquids and dimethyl sulfoxide mixed solvents. Eur Polym J 113:89-97. https://doi.org/10.1016/j.eurpolymj.2019.01.053

17. Jaworska MM, Stępniak I, Galiński M et al (2018) Modification of chitin structure with tailored ionic liquids. Carbohydr Polym 202:397-403. https://doi.org/10.1016/j.carbpol.2018.09.012

18. King C, Shamshina JL, Gurau G et al (2017) A platform for more sustainable chitin films from an ionic liquid process. Green Chem 19:117-126. https://doi.org/10.1039/c6gc02201d

19. Jabbour L, Bongiovanni R, Chaussy D et al (2013) Cellulosebased Li-ion batteries: a review. Cellulose 20:1523-1545. https:// doi.org/10.1007/s10570-013-9973-8

20. Sheng J, Tong S, He Z, Yang R (2017) Recent developments of cellulose materials for lithium-ion battery separators. Cellulose 24:4103-4122. https://doi.org/10.1007/s10570-017-1421-8

21. Xiao S, Wang F, Yang Y et al (2014) An environmentally friendly and economic membrane based on cellulose as a gel polymer electrolyte for lithium ion batteries. RSC Adv 4:76-81. https://doi.org/ 10.1039/C3RA46115G

22. Kaźmierczak-Raźna J, Półrolniczak P, Wasiński K et al (2019) Comparison of physicochemical, sorption and electrochemical properties of nitrogen-doped activated carbons obtained with the use of microwave and conventional heating. Adsorption 25:405417. https://doi.org/10.1007/s10450-019-00012-w

23. Dyatkin B, Presser V, Heon M et al (2013) Development of a green supercapacitor composed entirely of environmentally friendly materials. Chemsuschem 6:2269-2280. https://doi.org/ $10.1002 /$ cssc. 201300852

24. Jeong SS, Böckenfeld N, Balducci A et al (2012) Natural cellulose as binder for lithium battery electrodes. J Power Sources 199:331-335. https://doi.org/10.1016/j.jpowsour.2011.09.102

25. Böckenfeld N, Jeong SS, Winter M et al (2013) Natural, cheap and environmentally friendly binder for supercapacitors. J Power Sources 221:14-20. https://doi.org/10.1016/j.jpowsour.2012.07. 076

26. Wang Z, Tammela P, Strømme M, Nyholm L (2017) Cellulosebased supercapacitors: material and performance considerations. Adv Energy Mater 7:1-22. https://doi.org/10.1002/aenm. 201700130

27. Jiang L, Nelson GW, Han SO et al (2016) Natural cellulose materials for supercapacitors. Electrochim Acta 192:251-258. https:// doi.org/10.1016/j.electacta.2015.12.138

28. Pérez-Madrigal MM, Edo MG, Aleman C (2016) Powering the future: application of cellulose-based materials for supercapacitors. Green Chem 18:5930-5956. https://doi.org/10.1039/ C6GC02086K

29. Kasprzak D, Stępniak I, Galiński M (2018) Electrodes and hydrogel electrolytes based on cellulose: fabrication and characterization as EDLC components. J Solid State Electrochem 22:30353047. https://doi.org/10.1007/s10008-018-4015-y

30. Simon P, Gogotsi Y (2008) Materials for electrochemical capacitors. Nat Mater 7:845-854. https://doi.org/10.1038/nmat2297

31. Béguin F, Frackowiak E (2013) Supercapacitors: materials, systems, and applications

32. Piwek J, Platek A, Fic K, Frackowiak E (2016) Carbon-based electrochemical capacitors with acetate aqueous electrolytes. Electrochim Acta 215:179-186. https://doi.org/10.1016/J.ELECTACTA. 2016.08.061
33. Xia L, Yu L, Hu D, Chen GZ (2017) Electrolytes for electrochemical energy storage. Mater Chem Front 1:584-618. https://doi.org/ 10.1039/c6qm00169f

34. Galiński M, Lewandowski A, Stępniak I (2006) Ionic liquids as electrolytes. Electrochim Acta 51:5567-5580. https://doi.org/10. 1016/j.electacta.2006.03.016

35. Ye W, Wang H, Ning J et al (2021) New types of hybrid electrolytes for supercapacitors. J Energy Chem 57:219-232. https://doi. org/10.1016/j.jechem.2020.09.016

36. Fernicola A, Scrosati B, Ohno H (2006) Potentialities of ionic liquids as new electrolyte media in advanced electrochemical devices. Ionics (Kiel) 12:95-102. https://doi.org/10.1007/ s11581-006-0023-5

37. Yang P, Mai W (2014) Flexible solid-state electrochemical supercapacitors. Nano Energy 8:274-290. https://doi.org/10.1016/j. nanoen.2014.05.022

38. Choudhury NA, Sampath S, Shukla AK (2009) Hydrogel-polymer electrolytes for electrochemical capacitors: an overview. Energy Environ Sci 2:55-67. https://doi.org/10.1039/B811217G

39. Zhong C, Deng Y, Hu W et al (2015) A review of electrolyte materials and compositions for electrochemical supercapacitors. Chem Soc Rev 44:7484-7539. https://doi.org/10.1039/C5CS00303B

40. Iwakura C, Wada H, Nohara S et al (2003) New electric double layer capacitor with polymer hydrogel electrolyte. Electrochem Solid-State Lett 6:2002-2004. https://doi.org/10.1149/1.1535752

41. Fard HN, Pour GB, Sarvi MN, Esmaili P (2019) PVA-based supercapacitors Ionics (Kiel) 25:2951-2963. https://doi.org/10.1007/ s11581-019-03048-8

42. Lin S, Wang F, Shao Z (2021) Biomass applied in supercapacitor energy storage devices. J Mater Sci 56:1943-1979. https://doi.org/ 10.1007/s10853-020-05356-1

43. Shen X, Shamshina JL, Berton P et al (2015) Hydrogels based on cellulose and chitin: Fabrication, properties, and applications. Green Chem 18:53-75. https://doi.org/10.1039/c5gc02396c

44. Stepniak I, Galinski M, Nowacki K et al (2016) A novel chitosan/ sponge chitin origin material as a membrane for supercapacitors preparation and characterization. RSC Adv 6:4007-4013. https:// doi.org/10.1039/C5RA22047E

45. Deng L, Zhang LM (2020) Rheological characteristics of chitin/ ionic liquid gels and electrochemical properties of regenerated chitin hydrogels. Colloids Surfaces A Physicochem Eng Asp 586:124220. https://doi.org/10.1016/j.colsurfa.2019.124220

46. Kasprzak D, Galiński M (2021) DMSO as an auxiliary solvent in the fabrication of homogeneous chitin-based films obtaining from an ionic liquid process. Eur Polym J 158:110681. https://doi.org/ 10.1016/j.eurpolymj.2021.110681

47. Fic K, Lota G, Meller M, Frackowiak E (2012) Novel insight into neutral medium as electrolyte for high-voltage supercapacitors. Energy Environ Sci 5:5842-5850. https://doi.org/10.1039/ c1ee02262h

48. Ratajczak P, Jurewicz K, Béguin F (2014) Factors contributing to ageing of high voltage carbon/carbon supercapacitors in salt aqueous electrolyte. J Appl Electrochem 44:475-480. https://doi. org/10.1007/s10800-013-0644-0

49. Ratajczak P, Jurewicz K, Skowron P et al (2014) Effect of accelerated ageing on the performance of high voltage carbon/carbon electrochemical capacitors in salt aqueous electrolyte. Electrochim Acta 130:344-350. https://doi.org/10.1016/j.electacta.2014.02. 140

50. Duan Y, Freyburger A, Kunz W, Zollfrank C (2018) Cellulose and chitin composite materials from an ionic liquid and a green cosolvent. Carbohydr Polym 192:159-165. https://doi.org/10.1016/j. carbpol.2018.03.045

51. Nowacki K, Stępniak I, Langer E et al (2020) Electrochemical approach for isolation of chitin from the skeleton of the black coral 
Cirrhipathes sp. (Antipatharia). Mar Drugs 18(6):297. https://doi. org/10.3390/md18060297

52. Wang X, Wang Z, Peak D et al (2018) Quantification of Coexisting Inner- and Outer-Sphere Complexation of Sulfate on Hematite Surfaces. ACS Earth Sp Chem 2:387-398. https://doi.org/10. 1021/acsearthspacechem.7b00154

53. Kiefer J, Strk A, Kiefer AL, Glade H (2018) Infrared spectroscopic analysis of the inorganic deposits from water in domestic and technical heat exchangers. Energies 11:798. https://doi.org/ 10.3390/en 11040798

54. Cárdenas G, Cabrera G, Taboada E, Miranda SP (2004) Chitin characterization by SEM, FTIR, XRD, and13C cross polarization/mass angle spinning NMR. J Appl Polym Sci 93:1876-1885. https://doi.org/10.1002/app.20647
55. Navarra MA, Dal Bosco C, Moreno JS et al (2015) Synthesis and characterization of cellulose-based hydrogels to be used as gel electrolytes. Membranes (Basel) 5:810-823. https://doi.org/10. 3390/membranes5040810

56. Idenoue S, Oga Y, Hashimoto D et al (2019) Preparation of reswellable amorphous porous celluloses through hydrogelation from ionic liquid solutions. Materials (Basel) 12:1-8. https://doi. org/10.3390/ma12193249

Publisher's Note Springer Nature remains neutral with regard to jurisdictional claims in published maps and institutional affiliations. 